\title{
First Record of the Subfamily Psychodinae (Diptera: Psychodidae) from Ecuador
}

Francisco Collantes ${ }^{1}$ and Enrique Baquero ${ }^{2}$

${ }^{1}$ Departament of Animal Biology (Zoology), Murcia University, Murcia, Spain;

${ }^{2}$ Departament of Zoology and Ecology, University of Navarra, Pamplona, Spain

\section{ABSTRACT}

This is the first record for the subfamily Psychodinae from Ecuador and a new species belonging to genus Arisemus, A. triconnectus, is described.

\section{KEYWORDS}

Psychodidae, Psychodinae, Arisemus triconnectus, new species, Ecuador, Neotropical.

$$
\begin{aligned}
& \text { Address correspondence to: } \\
& \text { Francisco Collantes Alcaraz } \\
& \text { Departamento de Biología Animal (Zoología) } \\
& \text { Facultad de Biología, Universidad de Murcia } \\
& \text { Campus de Espinardo, } 30100 \text { Murcia, Spain } \\
& \text { E-mail: Fcollant@fcu.um.es }
\end{aligned}
$$

\section{INTRODUCTION}

The family Psychodidae has been known from Ecuador since 1950 (Rodriguez, 1950, quoted in Hashiguchi \& Gomez, 1987) through species of the subfamily Phlebotominae, vectors of the leishmaniasis, but there are no records of other subfamilies of Psychodidae.

\section{MATERIAL AND METHODS}

The specimens were collected with a Malaise trap situated in a clearing area of the Yasuni rainforest and preserved in $70 \%$ ethanol. The trap was working for a single time of 24 hours; 11706 arthropods, principally Diptera (72\%), Hymenoptera (10\%) and Hemiptera (7\%), were captured. The specimens were dissected and put on slides using DPX (Mixture of distyrene (polystyrene), plasticizer (tri-o-cresyl phosphate or dibutyl phathalate), and xylene) as embedding medium. A drawing mirror on a Nikon Labophot microscope wa s used to draw the taxonomically interesting parts. 
In the description of male terminalia, the location of parts is relative to the orientation of drawings, not to natural position.

The type material will be deposited in the collection of the University of Murcia, Spain, Departamento de Biología Animal (Zoología) (DBA).

\section{DESCRIPTION}

Arisemus triconnectus sp. n. (Figs. 1-6)

\section{Material examined}

Holotype. $\widehat{\jmath}$, ECUADOR: Napo, Estación Científica Yasuní (Pontificia Universidad Católica de Ecuador), $00^{\circ} 38^{\prime} \mathrm{S}$ 76 $30^{\prime} \mathrm{W}$, Malaise trap, 20/xi/95, E. Baquero \& F. Maza

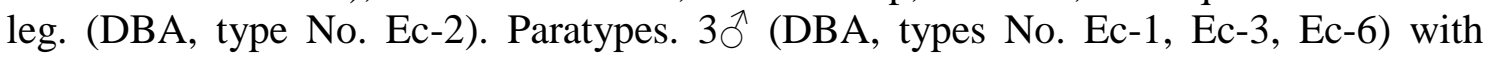
holotype.

Male. The head (Fig. 1) is longer than broad. Eyebridges of 3 facet rows, contiguous. Frons with undivided patch of scars. Vertex without naked midline. No enlarged postocular scars are present. The proportion of palpal segments is $1: 1.08: 1.04:$ - (last palpomere contracted and wrinkled). Large scape (Fig. 2), 3.3 times length of pedicel, both with dark scales. Flagellum slender; first three flagellomeres fusiform, broader than others and fused. Flagellomeres 4-11 with slight necks, ill-defined and small rims. Flagellomeres 12 and 13 reduced in size, globular and without neck. The last one is lost, but it may be supposed that this segment is reduced too (as in other species of Arisemus).

Wing (Fig. 3) $1.94 \mathrm{~mm}$ long, about 3 times as long as broad. Slightly brown spots at tip of all longitudinal veins. $\mathrm{R}_{\mathrm{s}}$ pectinate; radial and medial forks on the same level, basal of centre of wing, and complete. $\mathrm{R}_{2+3}$ very short, reduced to short stump anterior of the fork. $\mathrm{CuA}^{2}$ not expanded.

Terminalia (Fig. 4). with coxite shorter than style; the coxite shows a patch of scars on the outer side and three to four setae in the inner side. Style with a patch of scars in the broad base and slender distal half, with two short setae at the tip. Hypandrium sclerotised with slightly open V-shape. Gonocoxal apodemes (Fig. 5) broad, large, joined at the midline, with medial keel connected to aedeagus. Right rounded parabasal process (pbp). Aedeagal complex asymmetrical, with three distinctive pieces. On the left side a spatula-shaped piece (ssp), perhaps the paramere. On its inner side (following its margin) a pointed element (pe). On the outer side, the piece continues as a plate which runs over it and joins the hypandrium. This plate also continues below the piece to the right parabasal process. The aedeagus (ae), with hooked attenuated tip and, in part, below the left element, is in the middle of the aedeagal complex, arising from a basal ring. Cercopod with single retinaculum (Fig. 6). 


\section{Etymology}

'tri-' L, three, 'connectus' L, fused and continued in an alone unit; refers to the first three fused and connected flagellomeres.

\section{Diagnosis}

First three fused flagellomeres. Aedeagal complex with a lateral spatula-shaped piece and pointed and very hooked aedeagus.

\section{Habitat}

The specimens were collected in a $50 \times 50 \mathrm{~m}$ clearing in a tropical rainforest, on a hillside north of the Yasuní Biological Station (Pontifical Catholic University of Ecuador), at an altitude of $280 \mathrm{~m}$. Humidity was $90 \%$.

\section{DISCUSSION}

The males of 13 species belonging to genus Arisemus are known (Table 1). All occur in the Neotropics: Cuba (Botosaneanu \& Vaillant, 1970), Jamaica (Dyar, 1926; Satchell, 1955), Nicaragua (Collantes \& Martínez-Ortega, 1999), Costa Rica (Quate, 1996), Panama (Rapp, 1945) and Colombia (Wagner, 1994).

At first glance, they can be separated in two groups: with simple or forked style, respectively (Table 1). The forked style seems to be a secondary and independent differentiation. That this character originated more than once in the genus Arisemus is suggested by the very different structure of the forked styles.

On the other hand, 7 males show an aedeagal complex with similar arrangement: A. atrasetus, A. grabahamana, A. guhli, A. lepidotos, A. salazari, A. stylofurcatus, and the new species. All have a short parabasal process, a lateral and broad piece, with a pointed element in the inner side, and a curved and pointed aedeagus, which arises from a basal ring. We believe that the similar arrangement of the aedeagal complex is more important than the simple or forked styles as criterion for establishing the relationship in Arisemus.

The new species can be distinguished from its related species, A. atrasetus, A. grabahamana, A. guhli, A. lepidotos, A. salazari, A. stylofurcatus, by the first three fused flagellomeres. Another important character is the lateral spatula-shaped piece and the strongly hooked aedeagus.

\section{REFERENCES}

- Botosaneanu L, Vaillant F (1970): Trois Dipères Psychodidae noveaux de Cuba. Trav Lab Hydrobiol 61: 173-183. 
- Collantes F, Martínez-Ortega E (1999): A new species of moth-fly belonging to genus Arisemus Satchell, from Nicaragua (Diptera, Psychodidae). Aquatic Insects 21: 214-219.

- Dyar HG (1926): Some apparently new American psychodids (Dipera, Psychodidade). Insecutor Inscit menstr 14: 107-111.

- Hashiguchi Y, Gomez EAL (1987): Una breve revisión de la leishmaniasis en el Ecuador. In: Hasiguchi Y, ed., Estudios sobre la leishmaniasis en el Nuevo Mundo y su tratamiento con especial Referencia al Ecuador. Serie de reportes de investigación no. 1, pp. 4-16.

- Quate LW (1996): Preliminary taxonomy of Costa Rican Psychodidae (Diptera), exclusive of Phlebotominae. Revista de Biología Tropical 44 (Supplement I): 1-81.

- Rapp WF (1945): New Psychodidae from Barro Colorado Island. Journal of New York Entomology Society 53: 309-311.

- Satchell GH (1955): Two new subgenera of Psychodidae (Diptera) from Jamaica, with descriptions of five new species. Ann Mag nat Hist 12(8): 85-93

- Wagner R (1994): On a small collection of Psychodidae (Diptera) from Colombia. Stud Neotrop Fauna Env 29: 75-86. 
Table 1. Species of Arisemus, grouped by the simple or forked style. Group 1: style simple; Group 2: style forked.

\section{GROUP 1}

A. boxi (Satchell, 1955)

A. grabahmana (Dyar, 1926)

Jamaica, Colombia

A. martinezi Wagner, 1994

Jamaica

A. obandoi Wagner, 1994

Colombia

A. roessleri Wagner, 1994

Colombia

A. salazari Quate, 1996

Colombia

A. spilotos Quate, 1996

Costa Rica

Costa Rica

\section{GROUP 2}

A. atrasetus (Rapp, 1945)

Panama

A. guhli Wagner, 1994

Colombia

A. hexadactylus Botosaneanu \& Vaillant, 1970

Cuba

A. lepidotos Quate, 1996

Costa Rica

A. stylofurcatus (Collantes \& Martinez-Ortega, 1999)

Nicaragua

A. tetradactylus Botosaneanu \& Vaillant, 1970

Cuba 


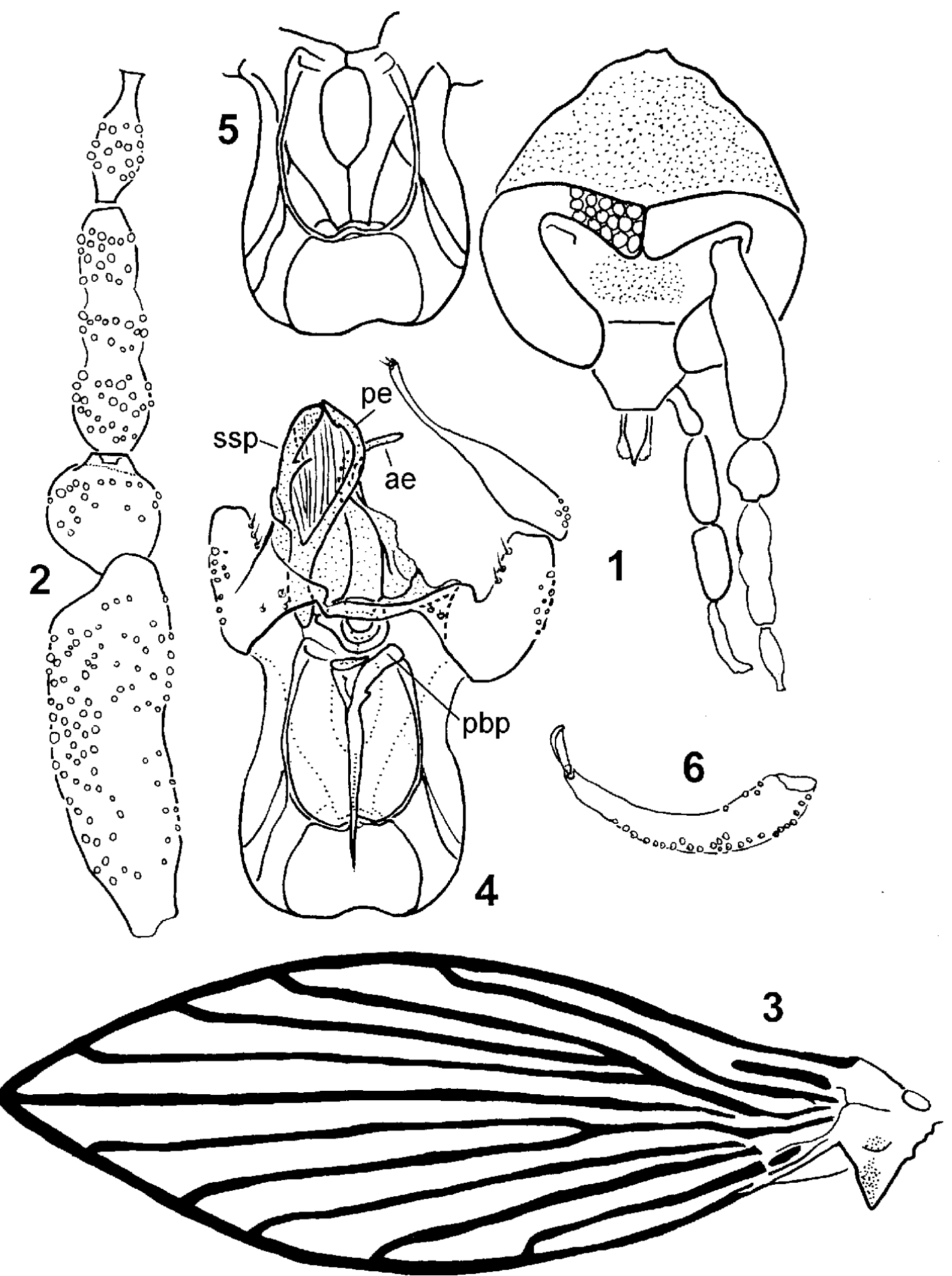

Figures 1-6. Arisemus triconnectus, sp. n.: (1) Head; (2) Base of antenna; (3) Wing; (4) Gonopods and aedeagal complex seen from above; (5) Gonocoxal apodemes and aedeagal apodeme; (6) Cercopod. Abbreviations: ae, aedeagus; pe, pointed element; pbp, right rounded parabasal process; ssp, spatula-shaped piece. 